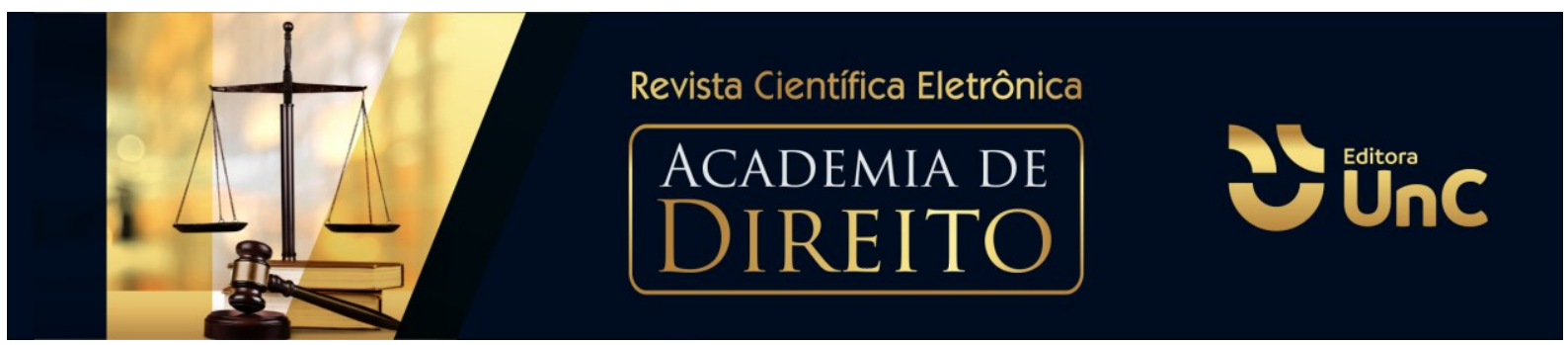

\title{
A INCONSTITUCIONALIDADE NA VEDAÇÃO À ESCOLHA DE REGIME DE BENS PARA PESSOAS ACIMA DE SETENTA ANOS DE IDADE
}

\author{
Franciane Suelin Ramos Soares Grein ${ }^{1}$ \\ Patricia Minini Wechinewsky²
}

\begin{abstract}
RESUMO
O presente trabalho tem como finalidade discutir sobre a imposição do regime de separação obrigatória de bens para os septuagenários exclusivamente pela idade. $\mathrm{O}$ problema proposto é como essa limitação imposta pelo inciso II do artigo 1.641 do Código Civil pode ferir princípios consolidados na Constituição Federal. A metodologia utilizada foi a revisão bibliográfica e jurisprudencial. Utilizou-se como critérios de delimitação a idade de 70 anos para os nubentes, a legislação civil brasileira, as decisões dos tribunais brasileiros e a Constituição Federal brasileira. Com essas análises, restou claro que uma pessoa que possui absoluto discernimento não deve ser limitada de um direito de escolha apenas pelo simples fato de ser idosa. É de extrema relevância evidenciar que a imposição do regime de separação obrigatória de bens aos septuagenários lesiona o que é de mais valioso na vida humana, qual seja a autonomia de escolha nos atos, bem como a dignidade da pessoa humana entre outros princípios Constitucionais. Restou demonstrada a confirmação da hipótese levantada, no sentido de ser inconstitucional tal imposição e a doutrina majoritária e alguns tribunais também já estão se posicionando pela inconstitucionalidade do aludido artigo 1.641 inciso II do Código Civil.
\end{abstract}

Palavras Chave: Casamento. Regime de Separação Total de Bens. Idade. Capacidade Civil. Inconstitucionalidade.

\footnotetext{
${ }^{1}$ Graduanda em Direito pela Universidade do Contestado Campus Mafra. Santa Catarina. Brasil. Email: francianesoares18@hotmail.com

2Possui graduação em Direito pela Universidade do Vale do Itajaí (2002). Atualmente é professora na Universidade do Contestado (UnC). Campus Canoinhas e Mafra-SC. Tem pós-graduação latu sensu em Direito Privado Contemporâneo pela Universidade do Contestado, em Direito Processual Civil pela Uniderp e em Tradução de Inglês na universidade Estácio de Sá. Cursa Mestrado na Universidad de La Empresa - Uruguai no programa de pós-graduação strictu sensu em Direito das Relações Internacionais e Integração da América Latina. Universidade do Contestado Campus Mafra. Santa Catarina. Brasil. E-mail: patricia.mw@professor.unc.br. ORCID https://orcid.org/0000$\underline{0002-8381-5867 .}$
} 


\title{
THE UNCONSTITUTIONALITY OF THE PROHIBITION OF CHOICE OF THE MATRIMONIAL PROPERTY REGIME TO THOSE ABOVE SEVENTY YEARS OLD
}

\begin{abstract}
The aim of the present study is to discuss the imposition of the regime of separation of matrimonial property to those above seventy years old. The problem that we have proposed is to show how this limitation of choice imposed by article 1.641, II of Brazilian Civil Code might hurt Constitutional Principles. The methodology we have used was bibliographical and case-laws review. The criteria we have established to this work were the age of seventy to the engaged couple (bride or groom), Brazilian civil legislation, Brazilian case-laws and Brazilian Federal Constitution. By means of the analysis it is clear that a person with total discernment must not have restricted his or hers right of choice by the simple fact of being elderly. It is of great significance to emphasize that the said imposition to those above seventy years old violates one of the most valuable rights of the human life which is the autonomy of choosing their acts as well as their dignity among other Constitutional Principles. The raised hypothesis is at the end confirmed since it is unconstitutional the said imposition so much that the majority of the legal theory as well as some case-laws are already deciding and positioning in terms of the unconstitutionality of the said article 1.641 II of the Brazilian Civil Code.
\end{abstract}

Key words: Wedding. Separation of Matrimonial Property. Age. Legal Capacity. Unconstitutionality.

\section{INTRODUÇÃO}

O legislador, ao impor o regime de separação obrigatório de bens para pessoas acima de 70 anos, possivelmente teve o intuito de salvaguardar o patrimônio de um ou de ambos os nubentes e seus herdeiros, ou mesmo a terceiros que viessem a ser lesados. Ocorre que alguns princípios constitucionais entram em conflito com o disposto em legislação infraconstitucional.

O presente trabalho tem foco nos nubentes brasileiros acima de 70 anos de idade e seu discernimento, bem como em analisar a inconstitucionalidade da norma infraconstitucional em face do direito à igualdade e à liberdade que estabelece que nenhuma pessoa pode ser discriminada em função do sexo ou da idade.

A pesquisa procura responder ao seguinte problema: Como as limitações na escolha dos nubentes quanto ao regime de bens, embasada exclusivamente na idade avançada conforme artigo 1.641 do código civil pode ferir princípios consolidados na Constituição Federal? 
Como hipótese à citada pergunta discute-se que 0 legislador infraconstitucional agiu de forma arbitrária e inconstitucional, concluindo certa inutilidade sem que ao menos o idoso acima de 70 anos fosse submetido a algum exame ou perícia para que pudesse aferir sua incapacidade para a escolha de regime de bens do casamento.

O objetivo geral consiste em analisar a inconstitucionalidade na vedação a escolha de regime de bens para pessoas acima de 70 anos de idade, levando em consideração a capacidade para casar e escolher o regime de bens. Os objetivos específicos consistem em abordar os princípios constitucionais que regem a capacidade civil e direito de personalidade, delimitando-se às pessoas acima de 70 anos, abordar conceitos de casamento e regime de bens analisando a inconstitucionalidade da aludida limitação e também expor a expectativa de vida nos tempos atuais do povo brasileiro.

A metodologia utilizada foi a revisão bibliográfica e jurisprudencial. Utilizou-se como critérios de delimitação a idade de 70 anos para os nubentes, a legislação civil brasileira, as decisões dos tribunais brasileiros e a Constituição Federal.

Em um primeiro momento explana-se sobre o casamento e sua evolução histórica seguindo de uma análise dos tipos de regimes de bens vigentes no Brasil bem como a capacidade para casar.

No item três apresentam-se os princípios constitucionais concernentes à discussão proposta e sua correlação com a inconstitucionalidade da imposição do regime de separação de bens no casamento dos maiores de 70 anos.

\section{DO CASAMENTO}

De casamento há numerosas definições que não se limitam às vezes a conceituá-lo, porém refletem concepções originais ou tendências filosóficas, posto que todos os sistemas o disciplinem, inexistente uniformidade na sua caracterização (PEREIRA, 2004, p. 51) ${ }^{34}$.

\footnotetext{
${ }^{3}$ Dentre as mais antigas definições de casamento, a figura de Modestino do século III, marcou o período clássico, dizendo: Nuptiae sunt coniunctio maris et feminae, consortium omnis vitae, divini et humani iuris communicatio. Tradução literal: "Núpcias são uma união em casamento de macho e fêmea, uma ação de toda a vida, a comunicação do direito divino e humano" (PEREIRA, 2002).
} 
A noção de família é muito anterior ao instituto de casamento, e o casamento como instituição, deriva efetivamente de um sistema organizado socialmente com o estabelecimento de regras formais, de fundo espiritual ou laico. Diante disso, as referências ao Direito Romano e ao sistema Canônico são fundamentais (GAGLIANO; PAMPLONA FILHO, 2016).

No Brasil a história aponta que o casamento serviu como forma de sedimentação da sociedade portuguesa que estava vivendo nas terras colonizadas, pois o instituto surge como uma forma de promover ligações entre as pessoas com o objetivo de criar células sociais (PIMENTEL, 2000).

A igreja católica exerceu grande influência no desenvolver do instituto, conforme aponta a história de um modo geral, como regulamentadora do casamento no mundo todo, pois sacramentou o instituto como sendo algo enviado por Deus, o qual jamais estaria sujeito ao rompimento pelo homem (DINIZ, 2008).

Por muitos anos a igreja católica exerceu os ditames do direito matrimonial, pois houve a edição de um decreto que determinava que os matrimônios fossem realizados com base no direito canônico (DINIZ, 2008).

O casamento católico, por muito tempo, foi considerado o único tipo de casamento que produzia efeitos no Brasil:

Até o advento da Lei 1.144/1861, que permitiu o casamento de não católicos, o casamento religioso era o único que produzia efeitos no Brasil. O casamento religioso foi substituído pelo casamento no civil, pelo Dec. 181/1890 (esta lei se utilizou do termo divórcio no sentido de separação de corpos) (NERY, 2013, p. 189).

A Constituição Federal de 1988 descreve uma revolução na forma de se entender uma constituição familiar, agora não obrigatoriamente originário de um casamento formal, mas fruto de uma "união estável", entre um homem e uma mulher, como entidade familiar velada pelo Estado, devendo a lei simplificar sua conversão em casamento, conforme descrito no artigo 226, $\S 3^{\circ}$ da Constituição Federal de 1988 (OLIVEIRA, 2003, p. 29).

\footnotetext{
${ }^{4}$ Da mesma maneira Pereira (2002) afirma que foi construída a definição elaborada por Ulpiano, consagrada nas Institutas de Justiniano, e depois adotada pelo Direito Canônico: nuptiae autem sive matrimonium est viri et mulieris coniunctio individuam vitae consuetudinem continens. Tradução literal: "União sem o casamento é uma conjunção entre homem e mulher com hábitos individuais de vida".
} 


\section{REGIME DE BENS E CAPACIDADE PARA CASAR}

A capacidade civil dos indivíduos situa-se regulamentada pelo Código Civil, sendo que o rol é taxativo, visto que a incapacidade civil não pode ser presumida, mas sim resulta da vontade da lei. A lei somente indica que são absolutamente incapazes os menores de 16 anos, como decide o artigo $3^{\circ}$ do Código Civil e em seu artigo $4^{\circ}$ estabelece o rol dos relativamente incapazes. Destaca-se que a figura do idoso maior de 70 anos não consta nem no citado rol de absolutamente incapazes, nem no rol dos relativamente incapazes.

No que se refere ao regime de bens, o Código Civil caracterizou quatro espécies: da comunhão universal, da comunhão parcial, da separação de bens e o de participação final nos aquestos. Entretanto, é permissível aos nubentes pactuar os preceitos desses regimes, ou elaborar recentes regras. Em nosso ordenamento acham-se quatro regimes de bens, via de regra, persiste a autodeterminação de vontade na escolha do regime como estabelece o artigo 1.639 do Código Civil (BRASIL, 2002).

\subsection{TIPOS E ESCOLHA DO REGIME DE BENS}

O desejo na seleção do regime matrimonial tem aspecto exclusivo estabelecido pelo legislador, sendo o pacto antenupcial, ou seja, é um tipo de contrato formal, realizado previamente ao matrimônio, pelo qual as partes indicam o regime de bens que prevalecerá entre eles no decorrer do matrimônio (RODRIGUES, 2000, p. 167-168). Esse pacto patrimonial requer escritura pública (artigo 1.653 do Código Civil) e competência para praticá-la. É ato individual e não pode ser delegado a outra pessoa (BRASIL, 2002).

O pacto antenupcial apesar de respeitar a escolha do casal considera os princípios da lei, os fins e a estrutura do casamento. Completa que esse pacto será nulo se não for realizado através de escritura pública e ineficiente caso não lhe ocorrer o casamento, nos termos do artigo 1.653, do Código Civil (RODRIGUES, 2000, p. 168). 


\subsubsection{Comunhão Universal de Bens}

O regime da comunhão universal de bens, até o surgimento da Lei $n^{\circ} 6.515$, de 1977, foi o que prevaleceu no direito brasileiro (RIZZARDO, 2008, p. 651).

Segundo prescrito no artigo 1.667 , do Código Civil, o regime da comunhão universal de bens é aquele no qual se comunicam os bens presentes e futuros dos cônjuges e suas dívidas passivas (DIAS, 2011, p. 240).

Há uma despersonalização do patrimônio individual, resultando em um patrimônio impartível e comum, sem estabelecer, descrever ou identificar a propriedade dos bens (RIZZARDO, 2008, p. 651). Apesar desta despersonalização, o artigo 1.668 do Código Civil estabelece que alguns bens não se comunicam, sendo excluídos da comunhão como por exemplo os bens doados ou herdados com cláusula de incomunicabilidade entre outros.

O regime da comunhão aparenta ser da Idade Média, não se alcançando estrutura semelhante no direito romano, em que prevaleceu o regime dotal e se fortaleceu na família medieval sob a intervenção da moral cristã, que pretendia a consolidar a unidade da família até no campo patrimonial (WALD, 2000, p. 106).

\subsubsection{Comunhão Parcial de Bens}

O regime da comunhão parcial de bens é visto como "regime legal", pois, é o regime vigente em caso de não haver convenção prévia ou no caso desta ser inválida ou ineficiente, conforme relatado no artigo 1.640, do Código Civil. Arnoldo Wald (2000, p. 113) complementa:

Com o advento da Lei $n^{\circ} 6.515$, de 26-12-1977, o regime da comunhão parcial passou a ser o legal, em substituição ao regime da comunhão universal. Na realidade, este último regime ficou bastante esvaziado com a reformulação legislativa decorrente da Lei $n^{\circ} 4.121$, de 27-8-1962, sendo certo que, desde o início da década de 70 , a doutrina mais recente e vários projetos cuidavam da introdução, no direito brasileiro, da comunhão de aquestos ou adquiridos como regime legal (Anteprojeto Miguel Reale, art. 1.838). 
Conforme disposto no artigo 1.658, do Código Civil, no regime da comunhão parcial, quando na constância do casamento, se comunicam os bens que sobrevieram ao casal.

O regime da comunhão parcial se define pela existência de três composições de bens, sendo eles o patrimônio da mulher, o do marido, e o patrimônio em comum, salienta que é o regime onde qualquer um dos cônjuges preserva como próprios os seus bens preliminares ao casamento, comunicando-se os obtidos obrigatoriamente na constância da sociedade conjugal (WALD, 2000, p. 113-114).

\subsubsection{Separação de Bens}

O regime de separação de bens é aquele em que o casamento não reflete no âmbito patrimonial (DIAS, 2011, p. 247).

No regime de separação de bens, cada um dos cônjuges preserva a posse a propriedade dos bens que trouxer para o casamento, assim como dos que forem a eles transmitidos, e dos que cada um conquistar a qualquer título na duração do casamento (PEREIRA, 2009, p. 242).

É um regime de bens não muito escolhido, porém de igual relevância que os demais. Consequentemente, os cônjuges detêm tão somente para si os bens que eram dispostos quando do matrimônio e a aqueles que obtêm ou vão obterem na vigência do casamento (RIZZARDO, 2008, p. 665).

Rizzardo (2008, p. 667) relata sobre as características do regime de separação de bens, de acordo com a transcrição que segue:

a) Propriedade plena e exclusiva pelos cônjuges dos bens existentes antes do casamento, e dos adquiridos na sua constância.

b) Administração exclusiva dos mesmos pelo respectivo cônjuge proprietário.

c) Livre disposição pelo cônjuge proprietário quanto aos bens moveis e imóveis, sem outorga ou o consentimento do outro na alienação ou oneração.

d) Em princípio, responsabilidade única na satisfação das obrigações pelo cônjuge que as contraiu, a menos se destinadas ao proveito comum.

e) Os eventuais créditos entre os cônjuges, especialmente os decorrentes de particulares, regulados pelo direito obrigacional aplicável a estranhos.

f) Contribuição mútua entre o marido e a mulher nas despesas da família, na proporção dos respectivos rendimentos. 
Para Wald (2000, p. 117), refere-se de um regime de estrutura simples, em que existem com total autonomia dois patrimônios diferentes, assim sendo o da mulher e o do marido. Ainda inclui que:

Tanto os bens anteriores como os posteriores à celebração do casamento são da propriedade individual de cada um dos cônjuges, o mesmo acontecendo com a responsabilidade pelas obrigações assumidas, que recaem sobre o cônjuge que praticou o ato.

Por meio do referido regime, os cônjuges conservam para si os bem que foi adquirido previamente ao casamento e aqueles que foram obtidos ou que serão adquiridos na vigência do matrimônio, ocorrendo a total separação do patrimônio dos consortes, não se tornando nada em comum. Nesse regime, será necessária a cooperação dos cônjuges para as despesas do casal na dimensão dos seus bens, do seu trabalho, e do seu rendimento, à exceção de disposição adversa no pacto antenupcial (TEIXEIRA; RIBEIRO, 2008, p. 395).

\subsubsection{Participação Finais nos Aquestos}

O regime de participação finais nos aquestos está narrado nos artigos 1.672 a 1.686 do Código Civil, sendo indispensável que os nubentes realizem o pacto antenupcial escolhendo por este regime.

É um regime patrimonial misto, híbrido, decorrendo de um mix entre as regras da separação convencional e da comunhão parcial de bens, uma vez que as regras são complexas de difícil entendimento e aplicação (DIAS, 2011, p. 243). É a participação final de ambos os cônjuges no patrimônio construído no decurso da sociedade conjugal a título oneroso (RIZZARDO, 2008, p. 662).

No regime de participação final nos aquestos cada cônjuge dispõe de patrimônio próprio e lhe compete, à época da ruptura da sociedade conjugal, direito à metade dos bens obtidos pelos cônjuges a título oneroso, na duração do matrimônio, conforme transcrito no artigo 1.672, do Código Civil.

Este patrimônio próprio é incorporado pelos bens que cada cônjuge possuía ao se matrimoniar e o por ele obtido, a qualquer título, durante o casamento, de acordo com o artigo 1.673, do Código Civil, que determina também, em seu 
parágrafo único, que cada cônjuge tem a administração exclusiva destes bens, e, que se os bens forem móveis, poderá livremente ser alienados.

Ocorrendo a dissolução do casamento, será averiguado o total dos aquestos, excluindo-se da soma dos patrimônios próprios os bens antecedentes ao matrimônio e os que em seu lugar se sub-rogam, os que vierem a cada cônjuge por sucessão ou autonomia e as dívidas relacionadas a esses bens, conforme o artigo 1.674, do Código Civil e seus incisos. O parágrafo único do mencionado artigo ressalta que, salvo prova em contrário, aparentam-se obtidos na constância do casamento os bens móveis.

Os bens não se partilham automaticamente, na forma dos regimes da comunhão parcial e da comunhão universal, somente na época da dissolução do casamento (divórcio ou morte) ocorrerá a partilha do acervo constituído a título oneroso na constância do casamento (RIZZARDO, 2008, p. 662).

\section{PRINCÍPIOS CONSTITUCIONAIS}

Os princípios podem ser expressos ou implícitos. Sendo os princípios constitucionais implícitos os que emanam da interpretação do sistema constitucional escolhido ou podem derivar da interpretação harmonizadora de normas constitucionais específicas como, por exemplo, o princípio da afetividade (PEREIRA, 2006, p. 844).

Há numerosos princípios constitucionais que são aplicados às normas infraconstitucionais, sendo encontrados no Código Civil, no Estatuto do Idoso, entre outras. Para efeitos da proteção da pessoa idosa em concordância com o Código Civil e o Estatuto do Idoso, serão ponderados exclusivamente os princípios constitucionais da dignidade da pessoa humana, da afetividade, da liberdade, e da isonomia e, portanto, serão estes os princípios aqui abordados.

\subsection{PRINCÍPIO DA DIGNIDADE DA PESSOA HUMANA}

Lôbo (2011, p. 60) em sua doutrina relata que a Constituição Federal da República preconiza como princípio fundamental do Estado Democrático de Direito e 
da ordem jurídica a dignidade da pessoa humana, sendo inserido este princípio no artigo $1^{\circ}$, inciso III da CF/88.

A dignidade da pessoa humana é particularmente comum a todas as pessoas humanas, como membros análogos do gênero humano, instituindo-se uma obrigação geral de proteção, respeito e intocabilidade. Também é visto como o princípio norteador do sistema jurídico uma vez que amplifica o indivíduo como principal fim de proteção e desenvolvimento de sua personalidade como propósito principal (LÔBO, 2011, p. 60).

Desta forma, a partir desse princípio, o legislador teve a intenção de amparar a pessoa em sua individualidade, visto que o ser humano é posto como o núcleo seja qual for o tipo de situação que possa envolvê-lo.

A definição da dignidade é algo imponderável, indisponível, não sendo objeto de permuta daquilo que tem um valor, seja monetário, seja estimatório. O referido doutrinador ainda menciona que no reino dos fins, tudo tem um preço, pode-se inserir em vez dela qualquer outra como correspondente; contudo, quando algo está acima de todo preço e, assim sendo, não permite equivalente, assim tem ela dignidade (KANT, 1986, p. 77).

Desta forma, infringiria o princípio da dignidade da pessoa humana todo ato ou conduta que tratasse algo ou alguém como coisa, sendo equiparado a uma coisa disponível ou a um objeto (LÔBO, 2011, p. 60).

Devido tal princípio e consoante artigo 230 da Constituição Federal que preconiza que o Estado tem o dever de amparar as pessoas idosas, foram criados microssistemas para garantir ainda mais a proteção da dignidade da pessoa humana, especificamente o Estatuto do Idoso.

Consequentemente, a dignidade da pessoa humana é intrínseca da pessoa, sem exceção de sua idade. Coerentemente, a formação desse princípio teve por finalidade atestar que a pessoa humana é titular de direitos, preservando o sujeito diante de seus semelhantes e da atuação do Estado, percebendo a probabilidade de se levar uma vida digna, e possivelmente, cobrar do Estado a concretização da satisfação das necessidades básicas para a sobrevivência (SANTIN; BOROWSKI, 2008). Desse modo, apesar do envelhecimento, é dever do Estado, da sociedade e de suas instituições assegurar a proteção da pessoa idosa e não limitar os seus direitos fundamentais. 


\subsection{PRINCÍPIO DA AFETIVIDADE E DA SOLIDARIEDADE}

O princípio da afetividade bem como o da solidariedade decorre do princípio da dignidade da pessoa humana. O princípio da solidariedade é, segundo Paulo Bonavides, o oxigênio da constituição, não apenas dela, pois a partir dela se difunde por todo ordenamento jurídico conferindo unidade de sentido e ganhando a valoração da ordem normativa constitucional (BONAVIDES, 1998, p. 259).

No mundo contemporâneo, procura-se a paridade entre o espaço público e o espaço privado do indivíduo sendo fundamental a solidariedade como elemento conformador dos direitos subjetivos. No direito de família, o princípio está no dever imposto à sociedade, o Estado e a família de proteção ao grupo familiar (artigo 226 da Constituição Federal), a criança e ao adolescente (artigo 227 da Constituição Federal) e especialmente ao idoso, segundo o artigo 230 da Constituição Federal (LÔBO, 2011, p. 63).

O princípio da afetividade está implícito na Constituição Federal e fundamenta-se no equilíbrio das relações socioafetivas e na comunhão de vida, com prioridade sobre as considerações de caráter patrimonial ou biológico (LÔBO, 2011, p. 70). É, portanto, a obrigação exigida aos pais em relação aos filhos e destes em relação àqueles, ainda que exista ausência de afeto entre eles, deixando de refletir somente com o falecimento de um dos sujeitos.

\subsection{PRINCÍPIO DA IGUALDADE}

A Constituição em seu artigo $3^{\circ}$ inciso IV trata como fundamentos do Estado Democrático de Direito a dignidade da pessoa humana e a cidadania no qual impede explicitamente qualquer forma de discriminação por motivo do sexo, da idade, ou da cor das pessoas, sendo assim, não tolera, em qualquer possibilidade, a idade versar em ocorrência de restrição aos fundamentos do Estado do Direito.

Lôbo (2011, p. 66) menciona que o princípio da igualdade bem como os outros princípios constitucionais não é de aplicabilidade absoluta, isto é, aceita limitações que não infrinjam o núcleo essencial. Como definição de justiça, necessitam-se tratar os desiguais na medida de suas desigualdades. Como 
resultado não desrespeita o princípio da igualdade a imposição no que diz respeito à religião ou sexo pertencente ao serviço ou função (FERREIRA FILHO, 2008, p. 283).

O princípio da igualdade de forma constitucional reflete que apenas a constituição pode dar validade e abrir prerrogativas. Consequentemente, para que ocorra uma dessemelhança na aplicação da lei essencialmente em virtude da idade, é necessário estar mencionado na constituição, quando não tal norma é tida como inconstitucional (FERREIRA FILHO, 2008, p. 284).

Nessa perspectiva, o princípio é uma contenção ao legislador e regra de compreensão. Como limite ao legislador, o princípio da igualdade impede a publicação de normas que determinam regalias por causa de sexo, classe social, cor ou até mesmo idade. Como tal característica do princípio de interpretação vez que o juiz deverá interpretar as normas de modo que não se privilegie determinado grupo (FERREIRA FILHO, 2008, p. 282).

Ainda assim, o princípio da igualdade estabelece que todos desfrutam de igualdade de direito em princípios. Desta forma, qualquer discriminação quanto ao desfrute dos direitos precisa ser expressa ou implicitamente mencionada na Constituição Federal. Com o princípio da igualdade, a ordem jurídica tenciona sustentar a impossibilidade de distinções fortuitas ou injustificadas. Portanto o sistema normativo, impondo a igualdade, garante que os preceitos genéricos ou concretos colham a todos sem especificações arbitrárias, não podendo estabelecer distinções unicamente em virtude de idade cronológica e então subtrair a liberdade e a autonomia das pessoas, sendo assim proveitosas do que lesivos para os atingidos (MELLO, 2012, p. 15).

Diante do exposto, as leis infraconstitucionais não podem instituir diferenças apenas devido à idade cronológica e então reduzir a liberdade e a autonomia das pessoas, como se as aptidões e capacidade intelectual fossem estabelecidas exclusivamente em virtude da contagem do tempo e como se o tempo fosse fator decisório para retirar do sujeito o direito de se autodeterminar (MADALENO, 2008, p. $30)$.

O preconceito com os idosos vem caracterizando uma forma de discriminação e de desrespeito com o valor não apenas da igualdade, mas sim da dignidade da pessoa humana. A idade não é tida como inabilidade da pessoa para o livre exercício da vida civil, principalmente se considerar que, com os avanços na medicina, tem-se 
o prolongamento da sobrevivência da pessoa humana, consequentemente a velhice chega a um tempo mais distante (MADALENO, 2008, p. 30).

\subsection{PRINCÍPIO DA LIBERDADE}

No que se refere aos direitos inerentes à segurança pessoal o direito à liberdade é um princípio destacado na Constituição Federal como um dos mais poderosos. A Constituição Federal/88 tem como objetivo fundamental construir uma sociedade livre, justa e solidária, conforme o artigo $3^{\circ}$ inciso I da Lei Maior.

O direito da liberdade está definido entre os direitos de primeira geração, vistos como a base do edifício democrático, liberdade esta que não pode tolerar limitações sob pena de todo o edifício desmoronar. Em função de tal princípio está declaradamente ordenado na Constituição Federal da República Federativa do Brasil, como objetivo fundamental, que a sua não aplicabilidade seria caso incomum necessitando semelhantemente estar previsto na Carta Magna (BESTER, 2005, p. 588).

Referente ao princípio da liberdade compreende-se que o homem pode potencializar todas as suas capacidades não havendo nenhum obstáculo quanto a isso, salvo em virtude de lei. É necessário da mesma forma que a liberdade respeite o direito de outrem porque adiante dessa fronteira haverá abuso, arbitrariedade e prepotência (COSTA, 1992, p. 123).

Madaleno (2008, p. 30) destaca que na esfera do direito de família, o princípio da liberdade é extensivamente aplicado, especialmente na escolha da constituição de uma unidade familiar entre casamento e união estável proibido por lei a intervenção de pessoa pública ou privada conforme estabelece o artigo 1513 do Código Civil Brasileiro. As pessoas têm livre decisão acerca do planejamento familiar (artigo 1556 do Código Civil Brasileiro) só podendo intervir o Estado para propiciar educação (DINIZ, 2002, p. 21).

Além disso, é de livre escolha dos cônjuges a decisão do regime matrimonial, conforme expressamente definido no Código Civil Brasileiro, em seu artigo 1.639 $\S$ $2^{\circ}$, constituindo um prejuízo cercear essa mesma escolha de regime de bens aos que completam 70 anos de idade (MADALENO, 2008, p. 30). 


\section{A INCONSTITUCIONALIDADE DA IMPOSIÇÃO DE SEPARAÇÃO DE BENS NO CASAMENTO DOS MAIORES DE 70 ANOS}

Constitucionalidade e inconstitucionalidade indicam ideias de relação, ou seja, o vínculo que se indica entre uma coisa tal como a Constituição e outra como um comportamento que lhe está ou não conforme, que com ela é ou não harmonizável, que cabe ou não no seu sentido. É essa relação de índole normativa que evidencia a inconstitucionalidade, pois somente assim consegue-se afirmar a indispensabilidade do texto constitucional e a ineficácia de todo e qualquer ato normativo violador (MENDES, 2007, p. 951).

A doutrina majoritária entende que é inconstitucional o regime da separação obrigatória de bens ao idoso, tendo ela como integrantes Caio Mário da Silva Pereira, Cristiano Chaves de Farias, Carlos Roberto Gonçalves, Maria Berenice Dias, Maria Helena Diniz, Nelson Rosenvald, Silvio Venosa, Silvio Rodrigues, entre vários outros.

O Código Civil de 2002 trouxe várias modificações, entre elas a autonomia privada, no que se refere à escolha do regime de bens. Contudo, apesar de evoluído em determinados pontos, manifestou-se obsoleto ao restringir a escolha do regime de bens às pessoas maiores de setenta anos, direcionando contra as diretrizes do Estado Democrático de Direito e da Constituição Federal, quando estabelece no artigo 1.641, II, a obrigatoriedade do regime da separação de bens no casamento, para as pessoas maiores de 70 (setenta) anos.

A restrição à escolha do regime de bens pela pessoa maior de setenta anos defronta, em primeiro plano, o princípio constitucional da dignidade da pessoa humana, por limitar sua autonomia como pessoa e constrangê-lo a tutela reducionista, ainda estabelecer limitação à liberdade de contrair matrimônio, que a Constituição não faz. Assim sendo, é inconstitucional esse ônus (LÔBO, 2009, p. 302).

Este artigo 1641, II do Código Civil também afasta das pessoas com idade acima de setenta anos a chance de estabelecer questões patrimoniais relacionadas ao seu casamento, entra em conflito com o postulado da dignidade humana definida na redação constitucional, conforme posicionamento de Diniz: 
Tal restrição, convenhamos, é manifestamente inconstitucional, pois fere o princípio da dignidade da pessoa humana, na medida em que comporta uma intervenção na vida íntima do indivíduo, limitando a sua autonomia privada - o que não condiz com a principiologia do Estado Democrático de Direito (DINIZ, 2011, p. 132).

Ao mesmo tempo, o princípio da igualdade amparado pela Constituição Federal brasileira em seu art. $5^{\circ}$, caput, estabelece que todas as pessoas estão igualadas em capacidades e direitos, fundamento por qual precisam ser tratadas de forma semelhante pela legislação. Refere-se de um princípio que conduz tanto as atividades executivas e legislativas, quando da publicação de atos normativos e leis, quanto às atuações de intérprete e do particular na utilização do direito ao caso concreto. Em qualquer concepção, o ato aplicado não pode ser dilatoriamente baseado em critérios preconceituosos, discriminatórios, sexistas ou racistas (DINIZ, 2011).

Ao septuagenário, exclusivamente pelo quesito etário, embora se encontre em utilização de sua integral capacidade mental e intelectual, é apanhado o direito de escolher o regime desejado. Refere-se de uma norma proibitória vagamente imparcial, que proporciona um preconceito sobre a pessoa idosa sob a justificação de protegê-las, entretanto se sustenta em axiomas equivocados, especialmente a de que se deve defender o patrimônio em detrimento da sua dignidade, tal como que a pessoa que contrai núpcias com o idoso não se casa por amor e sim por interesse (MELLO, 2012, p. 14-15).

Em relação aos princípios constitucionais da dignidade da pessoa humana e da igualdade que são feridos pelo dispositivo em tela, Madaleno (2018), discute:

Tomando como ponto de partida o respeito à dignidade do idoso para
assegurar o seu espaço nas relações familiares e a sua participação nas
atividades sociais, deve ser alcançada a completa interação entre o
discurso e a prática, conciliando as normas constitucionais e
infraconstitucionais, para acioná-las não em proteção da idade, mas na
efetiva defesa da dignidade da pessoa, em qualquer faixa de idade
(MADALENO, 2018, p. 114).

Apesar de o propósito do legislador, para a limitação em observação, se amparar na proteção do idoso contra o interesse unicamente econômico de pessoas mal-intencionadas (CARVALHO FILHO, 2010, p. 1641), a lei não possui argumento econômico ou moral algum, visto que a incerteza contra o matrimônio dessas 
pessoas não tem motivo para sobrepor. Se é incontestável que podem acontecer esses casamentos por ganância nestas faixas etárias, indiscutível também que pode existir esse interesse em todas as idades (PEREIRA, 2009, p. 197).

Igualmente, o Princípio da solidariedade familiar que por seus ensinamentos nos levam a entender este princípio como resultante dos vínculos fraternos, percebendo em si o afeto e a reciprocidade (DIAS, 2015, p. 44) e que este é decorrente da superação do individualismo jurídico, no que concerne a superação do modo da sociedade viver e pensar baseado na primazia dos interesses individuais (LÔBO, 2011, p. 63).

Em razão deste princípio, a família busca a inclusão e o aperfeiçoamento do convívio coletivo, resultando na mutualidade de carinho que proporciona um ambiente sadio de crescimento para todos os integrantes que a constitui.

A liberdade deve condizer com os pressupostos fixados pela Constituição de 1988, visto que esta é que dá legalidade a liberdade, condizendo-se com ela. Afinal, em incerteza sempre se preponderara a liberdade, uma vez que é o direito que não se limita por conjecturas ou arbítrios que o vigora (SILVA, 2008, p. 71).

No tocante ao princípio da liberdade, não é este respeitado, já que não há liberdade de escolha do regime de bens nos casos vinculados às circunstancias do artigo 1.641 da lei infraconstitucional civil atual.

A Constituição Federal garante proteção especial ao idoso, assim como veda a discriminação em razão da idade. Portanto, ninguém pode ser discriminado em razão da sua idade, como se esta fosse motivo natural de incapacidade civil; dado que não há explicação para a restrição da capacidade de seja qual for o indivíduo, vez que:

Cada ser humano é humano por força de seu espírito, que o distingue da natureza impessoal e que o capacita para, com base em sua própria decisão, tornar-se consciente de si mesmo, de autodeterminar sua conduta, bem como de formatar a sua existência e o meio que o circunda (SARLET, 2001, p. 44).

Nos termos do artigo $5^{\circ}$ do Código Civil, em regra com a maioridade a capacidade civil, é compreendida como a capacidade plena da pessoa administrar sua vida, seus bens e sua aptidão para os atos da vida civil. 
Esta norma também viola o princípio da liberdade, visto que a limitação persiste exclusivamente para o casamento, não persistindo na união estável. Isto é, quem decidir-se pelo casamento é penalizado. O casamento e a união estável são formas autênticas de estabelecer família. Desse modo, os princípios constitucionais precisam conservar todos os valores e não meramente os do casamento. Necessitam serem garantidos os direitos não apenas dos nubentes, mas também das que se encontram em união estável. Não se trata unicamente de improcedente restrição que contraria o princípio constitucional da liberdade. Outrossim, há afronta ao princípio da igualdade ao se contemplar tratamento diferenciado entre a união estável e o casamento (DIAS, 2011).

Sendo certo que, independentemente da idade, algumas pessoas não dispõem de discernimento, estas devem enfrentar um processo judicial de interdição, sendo elas idosas ou não, o que estabelece condição exclusiva capaz de afastar a plena capacidade do indivíduo.

Ainda assim, o Código Civil não relata a velhice como motivo de incapacidade civil, até porque, em tal período da vida, não se presume a falta de lucidez.

\begin{abstract}
Ao se falar no estado da pessoa, toda cautela é pouca. A plena capacidade é adquirida quando do implemento da maioridade e só pode ser afastada em situações extremas e através do processo judicial de interdição (CPC 1.177 a 1.186). É indispensável não só a realização de perícia, mas também é obrigatório que o interditando seja interrogado pelo magistrado. Raros processos são revestidos de tantos requisitos formais, sendo imperiosa a publicação da sentença na imprensa por três vezes. Tal rigorismo denota o extremo cuidado do legislador quando trata da capacidade da pessoa (DIAS, 2013, p. 487).
\end{abstract}

De outra forma, os idosos sustentam legalmente conservados muitos direitos, como doar bens, exercer atividade profissional, votar, adotar pessoas e fazer testamento. A pessoa com idade acima de setenta anos, como qualquer outra pessoa, garante o direito à propriedade privada conforme o artigo $5^{\circ}$, XXII e 170, II da Constituição Federal, inclusive previsto no Código Civil de 2002 no artigo 1.228, sem nenhuma exceção. Tendo o direito à propriedade privada, pode voluntariamente optar em relação ao regime de bens. Maia Júnior (2012) discorre sobre o tema:

Observe-se que a própria Constituição Federal assegura ao maior de setenta anos a possibilidade de exercer profissão liberal ou atividade comercial ou industrial, ser Ministro de Estado, Deputado Federal, Senador 
da República, Vice-Presidente da República, Presidente da República, mas a Lei não Ihe permite o direito de escolher o regime de bens de casamento! (MAIA JÚNIOR, 2012, p. 195).

Assim, diante dos princípios da liberdade, dignidade da pessoa humana e igualdade nota-se uma discrepância com o inciso II do art. 1.641 do Código Civil, e confronta os motivos para se acreditar inconstitucional a previsão trazida no artigo 1.641, Il do Código Civil:

A primeira Justificativa é que a norma discrimina o idoso, afrontando o artigo $5^{\circ}$ da Constituição Federal. A segunda razão é que atenta contra a liberdade do indivíduo, fundada na sua dignidade humana (art. $1^{\circ}$, inc. III, da CF/88). A terceira é o desprezo ao afeto, fundado no princípio da solidariedade social e familiar (art. $3^{\circ}$, inc. I, da CF/88). A quarta justificativa é de que a norma protege excessivamente os herdeiros, sendo pertinente citar o dito popular que aduz: filho bom não precisa, filho ruim não merece. A quinta, e última, está relacionada à conclusão de que não se pode presumir a incapacidade de escolha de pessoa que tem mais do que essa idade (TARTUCE, 2011, p. 350-351).

Portanto, a exigência do regime da separação de bens, para as pessoas maiores de setenta anos, é inconstitucional. A avaliação da constitucionalidade das leis e atos revela-se, em último estudo, como a segurança maior de proteção da liberdade individual, acredita-se que este entendimento não ficará a mercê daqueles que, mesmo temporariamente, estão no poder (DANTAS, 2010, p. 56).

Este tema vem sendo discutido desde a promulgação do Código Civil atual, quando na I Jornada de Direito Civil, promovida pelo Centro de Estudos Judiciários do Conselho da Justiça Federal no ano de 2002 foi proposta a revogação do inciso II do artigo em tela. Madaleno 2018 expõe a justificativa:

\begin{abstract}
A norma que torna obrigatório o regime da separação absoluta de bens em razão da idade dos nubentes é manifestamente inconstitucional, malferindo o princípio da dignidade da pessoa humana, um dos fundamentos do Estado Democrático de Direito, inscrito no pórtico da Carta Magna (CF, art. $1^{\circ}$, inc. III). Isso porque introduz um preconceito quanto às pessoas idosas que, somente pelo fato de ultrapassarem determinado patamar etário, passam a gozar de presunção absoluta de incapacidade para alguns atos, como contrair casamento pelo regime de bens que melhor consulte seus interesses (MADALENO, 2018, p. 114).
\end{abstract}

Também, na III Jornada de Direito Civil promovida pelo Centro de Estudos Judiciários do Conselho da Justiça Federal, no ano de 2004 aprovou enunciados ( ${ }^{\circ}$ 
261 e 262) que sugerem a não aplicação deste dispositivo legal quando houvesse união estável anterior (MADALENO, 2018, p. 115).

Eis a decisão:

RECURSO ESPECIAL. DIREITO CIVIL. FAMÍLIA. MATRIMÔNIO CONTRAÍDO POR PESSOA COM MAIS DE 60 ANOS. REGIME DE SEPARAÇÃO OBRIGATÓRIA DE BENS. CASAMENTO PRECEDIDO DE LONGA UNIÃO ESTÁVEL INICIADA ANTES DE TAL IDADE. RECURSO ESPECIAL NÃO PROVIDO.

1. O artigo 258, parágrafo único, II, do Código Civil de 1916, vigente à época dos fatos, previa como sendo obrigatório o regime de separação total de bens entre os cônjuges quando o casamento envolver noivo maior de 60 anos ou noiva com mais de 50 anos.

2. Afasta-se a obrigatoriedade do regime de separação de bens quando o matrimônio é precedido de longo relacionamento em união estável, iniciado quando os cônjuges não tinham restrição legal à escolha do regime de bens, visto que não há que se falar na necessidade de proteção do idoso em relação a relacionamentos fugazes por interesse exclusivamente econômico.

3. Interpretação da legislação ordinária que melhor a compatibiliza com o sentido do art. $226, \S 3^{\circ}$, da CF, segundo o qual a lei deve facilitar a conversão da união estável em casamento.

4. Recurso especial a que se nega provimento (BRASIL. Superior Tribunal de Justiça. Quarta Turma, 2016, Grifo nosso).

Projetos de Leis como o de autoria do deputado Osório Adriano (DEM-DF), de $\mathrm{n}^{\circ} 4944 / 2009$, atualmente arquivado, que tinha por objetivo alterar artigo 1641, II, do Código Civil, passando a idade de 70 para 80 anos, em nada modifica a discriminação ao idoso, uma vez que a questão etária não é pressuposto para o discernimento, especialmente no que se refere à escolha de bens. Nesse sentido Farias e Rosenvald (2016, p. 312) ilustram:

\footnotetext{
Também nada adiantou o advento da Lei $\mathrm{n}^{\circ} 12.344 / 10$, aumentando a limitação de escolha do regime de bens de sessenta para setenta anos de idade, pois a violação à dignidade humana continua presente. A única solução cabível, em interpretação civil-constitucional, por certo, é desatrelar a idade das limitações impostas à escolha do regime de bens. Afinal, não se esqueça de que uma pessoa com setenta anos de idade pode (e isso acontece com frequência) chefiar o Poder Executivo e escolher os destinos econômicos de toda a nação, malgrado não possa, estranhamente, escolher o seu próprio regime de bens.
}

Esta imposição de obrigação é vergonhosa, pois trata o idoso como se não tivesse discernimento ou capacidade mental de escolher o regime de bens para pactuar no seu casamento. 
A inconstitucionalidade na vedação à escolha de regime de bens para pessoas acima de setenta anos de idade

Este limite desrespeita os princípios da autonomia da vontade, da isonomia, da liberdade, da dignidade da pessoa humana, porque presume que uma pessoa não tem capacidade mental ou discernimento meramente por ter completado setenta anos (FARIAS; ROSENVALD, 2016).

Tartuce (2016) declara que é um preconceito introduzido na legislação, sem suas palavras:

Isso porque introduz um preconceito quanto as pessoas idosas que, somente pelo fato de ultrapassarem determinado patamar etário, passam a gozar da presunção absoluta de incapacidade para alguns atos, como contrair matrimônio pelo regime de bens que melhor consultar seus interesses (TARTUCE, 2016, p. 143).

Além da doutrina, a jurisprudência vem adotando tal entendimento de inconstitucionalidade, conforme agravo de instrumento $n^{\circ} 70074075524$ do Tribunal de Justiça do Rio Grande do Sul:

AGRAVO DE INSTRUMENTO. AÇÃO DE INVENTÁRIO. COMPANHEIRA FALECIDA. PARTILHA DE BENS. REGIME DA SEPARAÇÃO OBRIGATÓRIA DE BENS. DESCABIMENTO. Às uniões estáveis, salvo documento escrito entre as partes, aplica-se o regime da comunhão parcial de bens, pelo qual se comunicam todos os bens adquiridos onerosamente no curso da convivência, independentemente da comprovação da efetiva participação de cada um dos companheiros, presumindo-se o esforço comum, a teor do disposto no art. 1.725 do CCB. Outrossim, não havendo na legislação a imposição do regime da separação obrigatória de bens, tal como ocorre no casamento quando um dos cônjuges contar 60 (sessenta) anos de idade (código anterior) ou 70 (setenta) anos de idade (código atual), descabida a aplicação da restrição por analogia pelo fato de causar flagrante prejuízo às partes. Ainda, a título de argumentação, mesmo que houvesse tal disposição, aplicar-se-ia o disposto na Súmula 377 do STF, pela qual comunicam-se os aquestos. Decisão reformada. RECURSO PROVIDO (RIO GRANDE DO SUL, 2017).

Ainda nesse sentido, a Arguição de Inconstitucionalidade $\mathrm{n}^{\circ}$ 10702096497335002 do Tribunal de Justiça de Minas Gerais reconhece:

INCIDENTE DE INCONSTITUCIONALIDADE - DIREITO CIVIL CASAMENTO - CÔNJUGE MAIOR DE SESSENTA ANOS - REGIME DE SEPARAÇÃO OBRIGATÓRIA DE BENS - ART. 258, PARÁGRAFO ÚNICO DA LEI 3.071/16 - INCONSTITUCIONALIDADE - VIOLAÇÃO DOS PRINCÍPIOS DA IGUALDADE E DA DIGNIDADE HUMANA. - É inconstitucional a imposição do regime de separação obrigatória de bens no casamento do maior de sessenta anos, por violação aos princípios da igualdade e dignidade humana (MINAS GERAIS, 2014). 
Nesse sentido, a Apelação Cível n. 0001747-33.2012.8.24.0159 do tribunal de Santa Catarina reconhece:

APELAÇÃO CÍVEL. AÇÃO DE DIVÓRCIO. SENTENÇA QUE DECRETOU A SEPARAÇÃO, DETERMINOU A PARTILHA DA RESIDÊNCIA DO CASAL NA PROPORÇÃO DE 50\% (CINQUENTA POR CENTO) PARA CADA E FIXOU ALIMENTOS NO PATAMAR DE 30\% (TRINTA POR CENTO) DO SALÁRIO MÍNIMO VIGENTE À EX-CÔNJUGE. RECURSO DO AUTOR. SEPARAÇÃO OBRIGATÓRIA DE BENS. CÔNJUGE SEXAGENÁRIO. ART. 1.641, INC. II, DO CC. PARTILHA. CASA CONSTRUÍDA NO CURSO DA RELAÇÃO EM TERRENO ADQUIRIDO ANTES DO MATRIMÔNIO. REGIME QUE NÃO IMPEDE A COMUNICAÇÃO DOS BENS FUTUROS, DESDE QUE DEMONSTRADO DE FORMA INEQUÍVOCA O ESFORÇO COMUM. SÚMULA 377, DO STF. EX-CÔNJUGE QUE PROVOU CONTRIBUIR COM A MÃO-DE-OBRA DA EDIFICAÇÃO. PARTILHA, TÃO SOMENTE, EM RELAÇÃO AO TRABALHO BRAÇAL DESPENDIDO. REFORMA DO DECISÓRIO, NESTE PONTO.

Não obstante haja a possibilidade comunicação dos bens adquiridos no curso do matrimônio regido pela separação obrigatória de bens, a partilha destes pressupõe a demonstração inequívoca de esforço comum despendido à aquisição do patrimônio futuro - ônus este que recai ao possível colaborador do crescimento patrimonial pré-existente a relação.

ALIMENTOS. DESNECESSIDADE. CARÁTER TRANSITÓRIO DA MEDIDA. AUSÊNCIA DE DEPENDÊNCIA ECONÔMICA DA ALIMENTANDA. IMPOSSIBILIDADE DO ALIMENTANTE. ARGUMENTOS RECHAÇADOS. VERIFICADA INVIABILIDADE DE SUBSISTÊNCIA PRÓPRIA. EX-CÔNJUGE ACOMETIDA DE LESÃO LOMBAR, NOS OMBROS E PÉS. AUSÊNCIA DE OUTRA FONTE DE RENDA. ARTS. $1.694 \mathrm{E} 1.695$, DO CC.

Em que pese o caráter transitório da prestação alimentar entre ex-cônjuges, uma vez verificada que a alimentanda não possui condições de promover, por trabalho, seu próprio sustento, bem como não inexistente nos autos prova de impossibilidade do alimentante em prestar-lhe auxílio sem prejuízo de seu sustento, à inteligência dos arts. 1.694 e 1.695, do CC, reputa-se legítima a mantença da obrigação alimentar. RECURSO PARCIALMENTE PROVIDO (SANTA CATARINA, 2012).

Também, a expectativa de vida e o envelhecimento populacional estão aumentando nos tempos modernos no Brasil, segundo o relatório do Banco Mundial a expectativa de vida será significativamente maior do que nas "sociedades mais desenvolvidas do século passado". As projeções são de que a população idosa Brasileira ira triplicar nas próximas quatro décadas (BANCO MUNDIAL, 2011).

Com a elevação da qualidade e da expectativa de vida, vem se alterando o perfil da terceira idade, que está a cada dia mais saudável e ativa. Com isso, a terceira idade tende a representar a cada ano uma maior parcela da população. Interessante destacar a colocação do Banco Mundial (2011): 


\begin{abstract}
A população idosa aumentará de $11 \%$ da população em idade ativa em 2005 para $49 \%$ em 2050 , enquanto que a população em idade escolar diminuirá de $50 \%$ para $29 \%$ no mesmo período. Essas variações na estrutura etária da população resultarão em maiores pressões fiscais sobre os sistemas públicos de saúde e previdência, enquanto as pressões fiscais sobre o sistema educacional financiado pelo governo diminuirão.
\end{abstract}

Desta forma, se verifica que o art. 1.641, inciso II, do Código Civil sofre de vícios de inconstitucionalidade, e não se compara com a realidade dos dias de hoje, em que o aumento dos idosos saudáveis é significativo. Com isso, a terceira idade tende a representar a maior parcela da população Brasileira e esta maior parte segue sendo desrespeitada pela imposição legal que aqui se discute.

\title{
6 CONSIDERAÇÕES FINAIS
}

O presente artigo versou em uma breve discussão sobre a inconstitucionalidade na vedação da opção de pessoas com mais de setenta anos em escolher o regime de bens que regerá seu matrimônio. A lei civil em algumas situações, tal como a em tela, afasta o direito de escolha dos cônjuges estabelecendo o regime da separação obrigatória.

Nessa toada o legislador se utilizou apenas de critérios etários a fim de proteger o patrimônio, afastando as questões emocionais de que supostamente o idoso não tem o direito de amar, formar uma família, concluindo arbitrariamente em cercear o direito de dispor dos seus bens de forma livre e espontânea, ferindo, assim, direitos fundamentais como a dignidade da pessoa humana, o princípio da igualdade e da liberdade.

O STJ ampliou levemente a liberdade de escolha do regime de bens dos nubentes acima de 70 anos para aqueles que comprovem união estável iniciada anteriormente a idade que dispõe o inciso II do artigo 1641 do Código Civil.

A doutrina majoritária também se posiciona no sentido da inconstitucionalidade desta vedação e, os tribunais brasileiros estão seguindo esse entendimento, conforme recortes de jurisprudências expostos no corpo do trabalho.

Assim, conclui-se que a hipótese levantada se confirma, pois, conforme os parâmetros e conceitos da legislação brasileira, mesmo com mais de 70 anos, o idoso é absolutamente capaz para exercer os atos da sua vida civil, seja para 
contrair núpcias por qualquer um dos regimes de bens, seja para praticar outros tipos de negócio, possuindo, portanto, a capacidade plena, sem a necessidade de auxílio para a prática dos seus atos.

Esse limite de idade é inconstitucional e vergonhoso, pois o que tem que ficar pactuado e claro é que se alguém por algum problema, por alguma deficiência o cônjuge não possuir discernimento, neste caso sim estaria obrigado a casar pelo regime de separação de bens, mas nunca pela idade. Sendo o caso dos ministros do Supremo Tribunal Federal, que podem julgar até os seus setenta e cinco anos e provam a sua capacidade técnica e a sua capacidade de discernimento julgando os casos mais importantes do nosso país.

Ante o exposto e, sob égide da Constituição Federal, resta claro que a lei infraconstitucional ao ferir os princípios constitucionais está contradizendo as bases da nossa Lei Maior, restando assim, inconstitucional o dispositivo que veda a liberdade de escolha dos nubentes em razão exclusiva da idade.

\section{REFERÊNCIAS}

BANCO MUNDIAL. Envelhecendo em um Brasil mais velho. Washington, D.C.: Banco Mundial, 2011. Disponível em: <http://siteresources.worldbank.org/ BRAZILINPOREXTN/Resources/3817166-1302102548192/Envelhecendo_Brasil_ Sumario_Executivo.pdf>. Acesso em: 25 set. 2018.

BESTER, Gisela Maria. Direito constitucional: fundamentos teóricos. São Paulo: Manole, 2005. v. 1.

BONAVIDES, Paulo. Curso de direito constitucional. São Paulo: Malheiros, 1998.

BRASIL. (Código Civil 2002). Lei n. 10.406, de 10 de janeiro de 2002. Institui o Código Civil. Disponível em: <http://www.planalto.gov.br/ccivil_03/LEIS/2002/ L10406.htm>. Acesso em: 10 fev. 2018.

. Constituição (1824). Constituição Política do Império do Brasil. Rio de Janeiro: Secretaria de Estado, 1824. Disponível em: <http://www.planalto.gov.br/ ccivil_03/Constituicao/Constituicao24.htm>. Acesso em: 15 nov. 2018.

. Constituição (1891). Constituição da República dos Estados Unidos do

Brasil. Rio de Janeiro: Senado, 1891. Disponível em: <http://www.planalto.gov.br/ ccivil_03/Constituicao/Constituicao91.htm>. Acesso em: 30 jan. 2018. 
. Constituição (1934). Constituição da República Federativa do Brasil. Rio de Janeiro: Senado, 1934. Disponível em: <http://www.planalto.gov.br/ccivil_03/ Constituicao/Constituicao34.htm>. Acesso em: 10 fev. 2018.

. Constituição (1937). Constituição da República Federativa do Brasil. Rio de Janeiro: Senado, 1937. Disponível em: <http://www.planalto.gov.br/ccivil_03/ Constituicao/Constituicao37.htm>. Acesso em: 10 fev. 2018.

. Constituição (1946). Constituição da República Federativa do Brasil. Rio de Janeiro: Senado, 1946. Disponível em: <http://www.planalto.gov.br/ccivil_03/ Constituicao/Constituicao46.htm>. Acesso em: 18 fev. 2018.

. Constituição (1967). Constituição da República Federativa do Brasil. Brasília: Senado, 1967. Disponível em: <http://www.planalto.gov.br/ccivil_03/ Constituicao/Constituicao67.htm>. Acesso em: 18 fev. 2018.

. Constituição (1988). Constituição da República Federativa do Brasil. Brasília: Senado, 1988. Disponível em: <http://www.planalto.gov.br/ccivil_03/ constituicao/constituicaocompilado.htm>. Acesso em: 10 nov. 2018.

. Decreto $n^{\circ} 1.144$, de 11 de setembro de 1861. Disponível em: <https://www2.camara.leg.br/legin/fed/decret/1824-1899/decreto-1144-11-setembro1861-555517-publicacaooriginal-74767-pl.html>. Acesso em: 16 set. 2019.

. Emenda Constitucional $\mathrm{n}^{\circ} 1$ de 1969. Edita o novo texto da Constituição Federal de 1967. Brasília: Senado, 1969. Disponível em: <http://www.planalto.gov.br/ ccivil_03/Constituicao/Emendas/Emc_anterior1988/emc01-69.htm>. Acesso em: 18 fev. 2018.

. Lei $\mathbf{n}^{\circ} 3.071$, de $1^{\circ}$ de janeiro de 1916. Promulga Código Civil dos Estados Unidos do Brasil. Disponível em: <http://www.planalto.gov.br/ccivil_03/leis/ L3071.htm>. Acesso em: 10 fev. 2018.

Lei n. ${ }^{\circ} 6.515$, de 26 de dezembro de 1977. Regula os casos de dissolução da sociedade conjugal e do casamento, seus efeitos e respectivos processos, e dá outras providências. Disponível em: <http://www.planalto.gov.br/ccivil_03/LEIS/ L6515.htm>. Acesso em: 19 fev. 2018.

. Superior Tribunal de Justiça. Quarta Turma. REsp 1318281/PE. Relatora Ministra Maria Isabel Gallotti. Julgado em: 01 dez. 2016. Diário da Justiça eletrônico, 07 dez. 2016

CARVALHO FILHO, Milton Paulo de. Código Civil comentado. Coordenador Cezar Peluzo. 4.ed. São Paulo: Manole, 2010.

COSTA, Célio Silva. A interpretação constitucional e os direitos e garantias fundamentais na Constituição de 1988. Rio de Janeiro: Liber Juris, 1992.

DANTAS, Ivo. O valor da Constituição. 3. ed. (Ed. histórica). Curitiba: Juruá, 2010.

Acad. Dir. (ISSNe: Em processo de criação) 
DIAS, Maria Berenice. Manual de direito das famílias. 10. ed. São Paulo: Revista dos Tribunais, 2015.

2011.

Manual de direito das famílias. 8.ed. São Paulo: Revista dos Tribunais,

. Manual de direito das famílias. 9.ed. atual. e ampl. São Paulo: Revista dos Tribunais, 2013.

DINIZ, Fernanda Paula. Direitos dos idosos na perspectiva civil-constitucional. Belo Horizonte: Arraes Editores, 2011.

DINIZ, Maria Helena. Curso de direito civil brasileiro: direito de família. 17. ed.

São Paulo: Saraiva, 2002, v. 5.

. Curso de direito civil brasileiro: direito de família. 23.ed. São Paulo:

Saraiva, 2008. v. 5.

FARIAS, Cristiano Chaves de; ROSENVALD, Nelson. Curso de direito civil: famílias. 8. ed. Salvador: Juspodivm, 2016.

FERREIRA FILHO, Manoel Gonçalves. Curso de direito constitucional. 34. ed. São Paulo: Saraiva, 2008.

GAGLIANO, Pablo Stolze; PAMPLONA FILHO, Rodolfo. Novo curso de direito civil: direito de família. 6. ed. São Paulo: Saraiva, 2016.

KANT, Immanoel. Fundamentação da metafísica dos costumes. Trad. Paulo Quintela. Lisboa: 70, 1986.

LÔBO, Paulo. Direito civil: famílias. 2. ed. São Paulo: Saraiva, 2009.

. Direito civil: famílias. 4. ed. São Paulo: Saraiva, 2011.

MADALENO, Rolf. Curso de direito de família. Rio de Janeiro: Forense, 2008.

Direito de família. 8.ed. Rio de Janeiro: Forense, 2018.

MAIA JÚNIOR, Mairan Gonçalves. O regime da comunhão parcial de bens no casamento e na união estável. 2. ed. rev. atual. e ampl. São Paulo: Revista dos Tribunais, 2012.

MELLO, Celso Antônio Bandeira de. O conteúdo jurídico do princípio da igualdade. 3. ed. São Paulo: Malheiros, 2012.

MENDES, Gilmar Ferreira; COELHO, Inocêncio Mártires; BRANCO, Paulo Gustavo Gonet. Curso de direito constitucional. 1ed. rev. e atual. São Paulo: Saraiva, 2007. 
MINAS GERAIS. Tribunal de Justiça. Arg Inconstitucionalidade $\mathrm{n}^{\circ}$ 649733528.2009.8.13.0702. 2014. Disponível em: <https://tj-mg.jusbrasil.com.br/ jurisprudencia/119528602/arg-inconstitucionalidade-arg-10702096497335002-mg>. Acesso em: 13 nov. 2018.

NERY, Rosa Maria de Andrade. Manual de direito civil: família. São Paulo: Revista dos Tribunais, 2013.

OLIVEIRA, Euclides. União estável: do concubinato ao casamento. 6.ed. 2. tiragem. São Paulo: Método, 2003.

PEREIRA, Caio Mário da Silva. Instituições de direito civil: direito de família. 14.ed. São Paulo: Forense, 2004. v. 5. Instituições de direito civil: direito de família. 17. ed. Rio de Janeiro: Forense, 2009. v. 5.

PEREIRA, Rodrigo da Cunha. Direito de família. São Paulo: IOB Tompson, 2006.

PIMENTEL, Helen Ulhôa. A construção das diferenças: Casamento e sexualidade em Paracatu, MG, no Século XVIII. 2000. Dissertação (Mestrado em História) Programa de Pós Graduação em História. Brasília, 2000.

RIO GRANDE DO SUL. Tribunal de Justiça. Agravo de Instrumento $\mathbf{n}^{\circ}$ 70074075524. Porto Alegre. 2017. Disponível em: <https://tjrs.jusbrasil.com.br/ jurisprudencia/495529435/agravo-de-instrumento-ai-70074075524-rs/inteiro-teor495529445? ref=juritabs\%20\%3E\%20Acesso\%20em:\%2025\%20set.,\%202018>. Acesso em: 13 nov. 2018.

RIZZARDO, Arnaldo. Direito de família: Lei n 10.406, de 10/01/2002. 6.ed. Rio de Janeiro: Forense, 2008.

RODRIGUES, S. Direito civil. 25. ed. São Paulo: Saraiva, 2000. v. 6.

SANTA CATARINA. Tribunal de Justiça. Apelação cível $n^{0} 0001747-$ 33.2012.8.24.0159. 2012. Disponível em: <https://tj-sc.jusbrasil.com.br/ jurisprudencia/667738953/apelacao-civel-ac-17473320128240159-armazem0001747-3320128240159/inteiro-teor-667739066?ref=topic_feed>. Acesso em: 23 set. 2019.

SANTIN, J.; BOROWSKI, M. O idoso e o princípio constitucional da dignidade humana. Revista Brasileira de Ciências do Envelhecimento Humano, v. 5, n. 1, 6 set. 2008. Disponível em: <http://seer.upf.br/index.php/rbceh/article/ view/261>. Acesso em: 13 jun. 2019.

SARLET, Ingo Wolfgan. Dignidade da pessoa humana e direitos fundamentais na constituição federal de 1988. Porto Alegre: Livraria do advogado, 2001. 
SILVA, José Afonso. Curso de direito constitucional positivo. 30 ed. São Paulo: Malheiros, 2008.

TARTUCE, Flávio. Artigos 1.639 A 1.657 CC. In.: ALVES, Leonardo Barreto Moreira (coord.). Código das famílias comentado. 2 ed. Belo Horizonte: Del Rey, 2011.

Direito civil: direito de família. 11. ed. Rio de Janeiro: Forense, 2016.

TEIXEIRA, Ana Carolina Brochado; RIBEIRO, Gustavo Pereira Leite. Manual de direito das famílias e das sucessões. Belo Horizonte: Del Rey: Mandamentos, 2008.

WALD, Arnoldo. $O$ novo direito de família. 13.ed. São Paulo: Saraiva, 2000.

Artigo recebido em: 09/08/2019

Artigo aceito em: 27/09/2019

Artigo publicado em: 20/11/2019 